Transportation Research Forum

Performance Evaluation of Coordinated Intersections with GPS Devices

Author(s): Yi Jiang, Shuo Li, and Zhonghua Zhao

Source: Journal of the Transportation Research Forum, Vol. 44, No. 3 (Fall 2005), pp. 77-91

Published by: Transportation Research Forum

Stable URL: http://www.trforum.org/journal

The Transportation Research Forum, founded in 1958, is an independent, nonprofit organization of transportation professionals who conduct, use, and benefit from research. Its purpose is to provide an impartial meeting ground for carriers, shippers, government officials, consultants, university researchers, suppliers, and others seeking exchange of information and ideas related to both passenger and freight transportation. More information on the Transportation Research Forum can be found on the Web at www.trforum.org. 


\section{Performance Evaluation of Coordinated Intersections with GPS Devices}

This paper presents methods for applying GPS devices to evaluate the performance of coordinated intersections in terms of traffic delays. It illustrates that GPS-recorded data provides detailed information on traffic delays of individual intersections as well as traffic delays of coordinated intersections as a whole system, including travel-time delay, stopped-time delay, time-in-queue delay, approach delay, and total delay. Most of these intersection delays are difficult to measure manually; however, with GPS-collected vehicle-positioning data, they can be either directly identified or indirectly derived. Methods for obtaining different types of intersection delays with GPS devices are introduced.

\section{by Yi Jiang, Shuo Li, and Zhonghua Zhao}

\section{INTRODUCTION}

Global positioning systems (GPS) have been used to conduct work zone studies (Jiang and $\mathrm{Li}$ 2002), congestion management studies (Quiroga and Bullock 1998a), and carfollowing analyses (Wolshon and Hatipkarasulu 2000). A California study (McNally et al. 2003) designed, developed, and tested a GPSbased in-vehicle data collection unit for traffic surveillance and management. The California data collection system incorporates GPS, data logging capabilities, two-way wireless communications, and a user interface in an extensible system which eliminates driver interaction. Ranjitkar et al. (2004) used a group of 10 test vehicles with GPS devices to record real-time car-following data to evaluate the performance of various traffic flow models. GPS devices have been used for travel-time studies by many researchers, including Jiang et al. (2002), Quiroga and Bullock (1998b), Turner (1996), and Van Aerde et al. (1993).

To further broaden the applications of GPS in transportation engineering, the objective of this study was to use GPS data to analyze various types of traffic delays at intersections. In this study, vehicle position data was recorded with a GPS device at selected coordinated intersections. Coordinated intersections are a set of intersections with coordinated green times that allow vehicles to move through the set of signals smoothly and efficiently. That is, the signals of coordinated intersections are programmed so they would maximize the chances of vehicles going through the intersections without stopping. It is often necessary to measure the performance of the signals in terms of traffic delays at the intersections. Intersection traffic delays include stopped-time delay, approach delay, travel-time delay, and time-in-queue delay. In practice, only the stopped-time delay is measured by traffic engineers because it is relatively easy to measure manually (McShane et al. 1998). Using GPS devices, all types of intersection delays can be measured with higher efficiency and accuracy. The study results demonstrate that traffic engineers can use GPS devices to evaluate the performance of coordinated intersections, to identify problem locations and time periods along the roadway, and to determine traffic control strategies for performance improvement.

\section{DATA COLLECTION}

The data collection was performed on two sets of coordinated intersections in Indiana, including a set of coordinated intersections on U.S. Highway 31 (US-31) in Kokomo and another set on State Road 26 (SR-26) in Lafayette. On the US-31 section, the coordinated intersections included the seven intersections from Lincoln Road to Sycamore Road. On the SR-26 section, the coordinated intersections included the eight intersections from Hammon Street (No. 1) to 
Progress Drive (No. 8). Figure 1 is the graphical illustrations of the two test roadway sections and their coordinated intersections. The number of runs (sample size) was determined through the following equation (Li et al. 2002):

(1) $\mathrm{n}=\left(\frac{\mathrm{Z}_{\alpha / 2} S}{e}\right)^{2}+\varepsilon_{\mathrm{n}}$

where

$\mathrm{n}$ = sample size (minimum number of test runs)

$\mathrm{S}=$ estimated standard deviation

$\mathrm{e}=$ limit of acceptable error in speed estimate

$\mathrm{Z}_{\alpha / 2}=$ Standard distribution with $(1-\alpha / 2)$ confidence level and n-1 degrees of freedom

$\varepsilon_{\mathrm{n}}=$ sample size estimation adjustment derived (Li et al. 2002)
For a $95 \%$ confident level or $\alpha=0.05$, the corresponding $\mathrm{Z}_{\alpha / 2}$ is 1.96 and $\varepsilon_{\mathrm{n}}$ is 3 . With an error of $\pm 5.0 \mathrm{~km} / \mathrm{h}$ speed estimate, the sample size was determined to be six for both of the test roadway sections.

A test vehicle with a GPS device, as shown in Figure 2, was used to record the vehicle positioning data. The GPS device, including the antenna and receiver, was used to receive satellite signal and output GPS position data. The external devices include a laptop computer and power supply devices. The laptop computer was employed to communicate with the GPS receiver and store the GPS position data. Figure 3 shows the GPS components. The GPS device error range is within 1.0 meter for distance measurements and is less than 0.16 kilometers per hour for speed measurements. This accuracy is considered sufficient for the purpose of traffic analysis.

Figure 1: Layout of the Test Roadway Segments

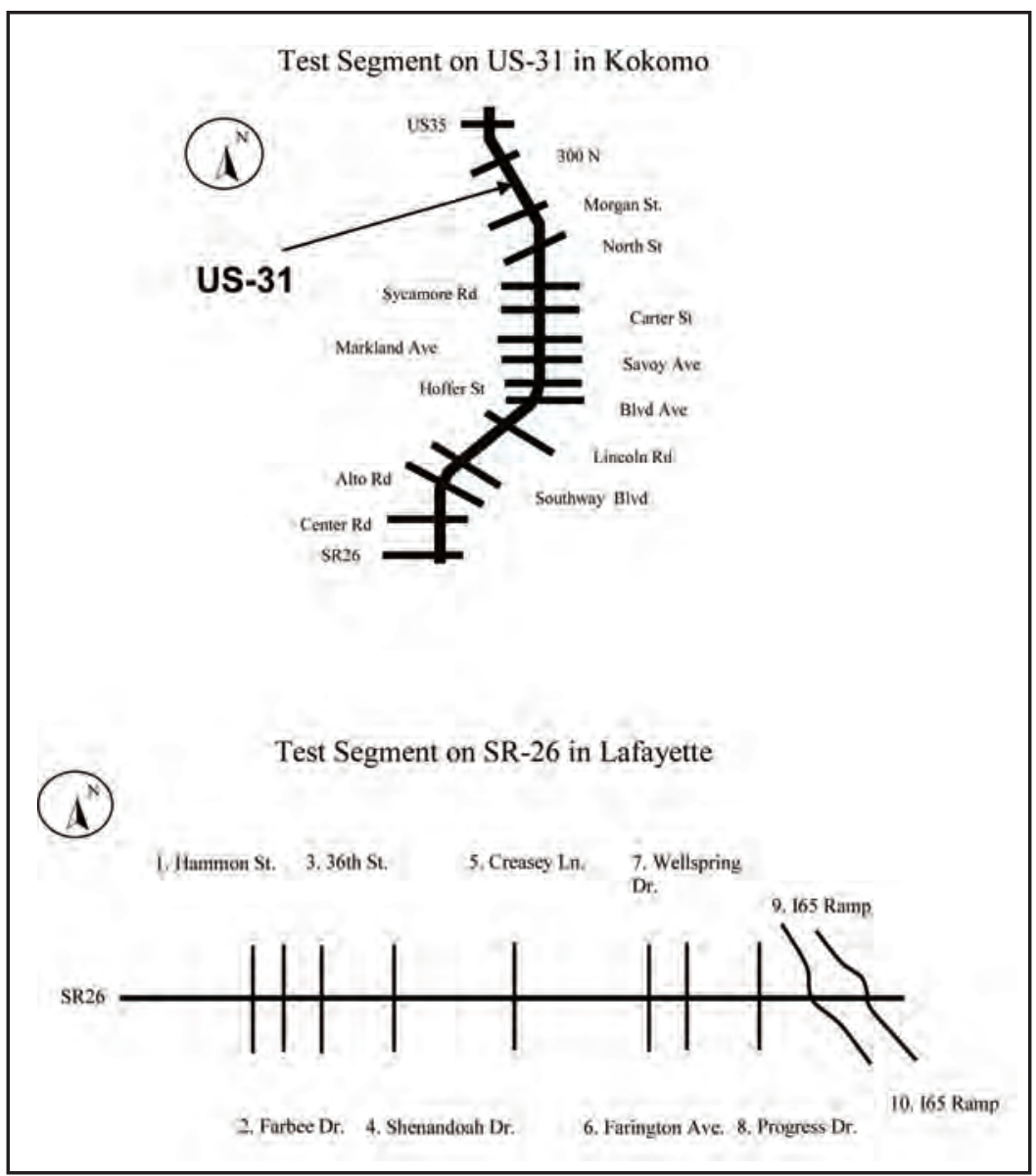


Figure 2: Test Car for GPS Traffic Data Collection

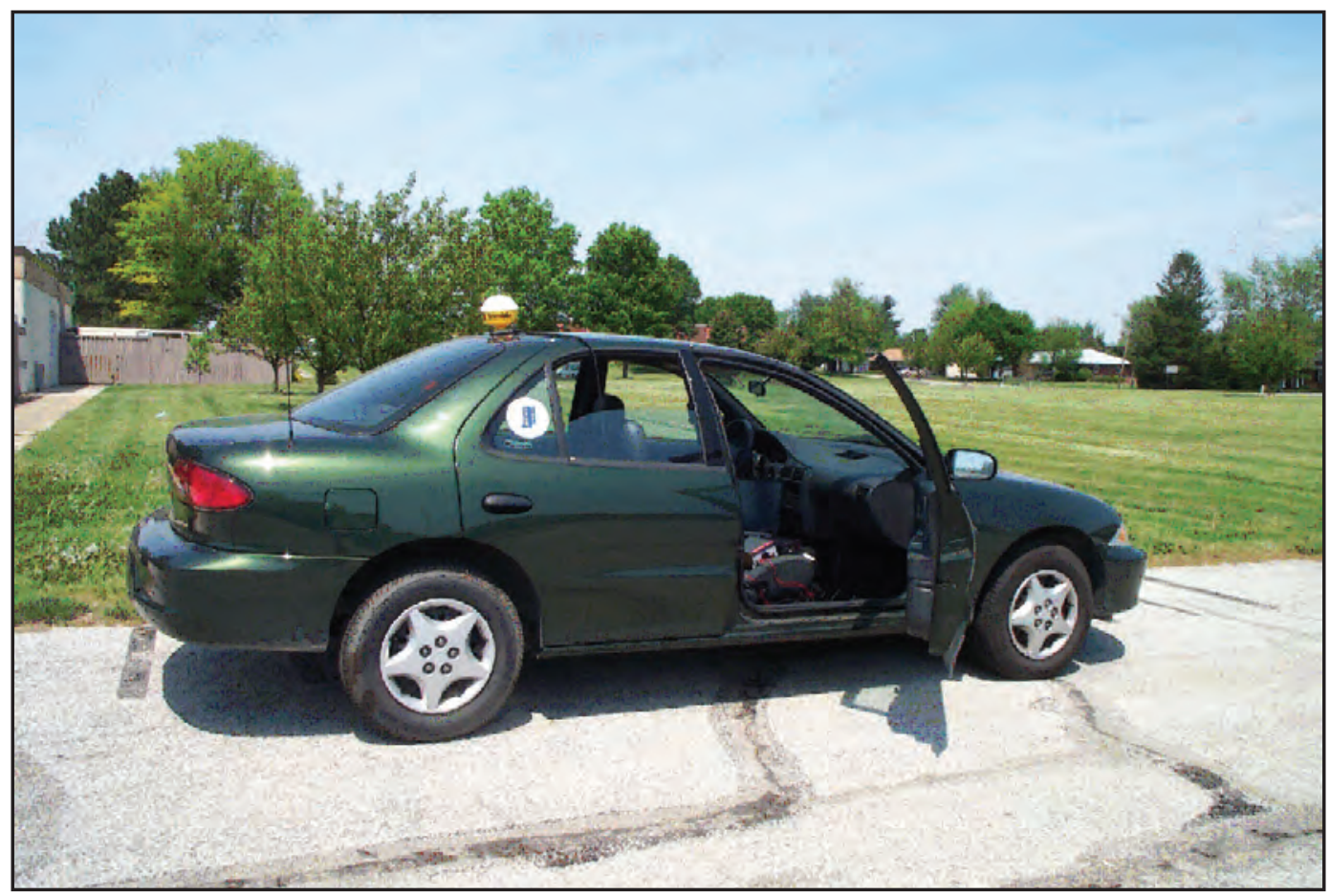

Figure 3: GPS and External Devices

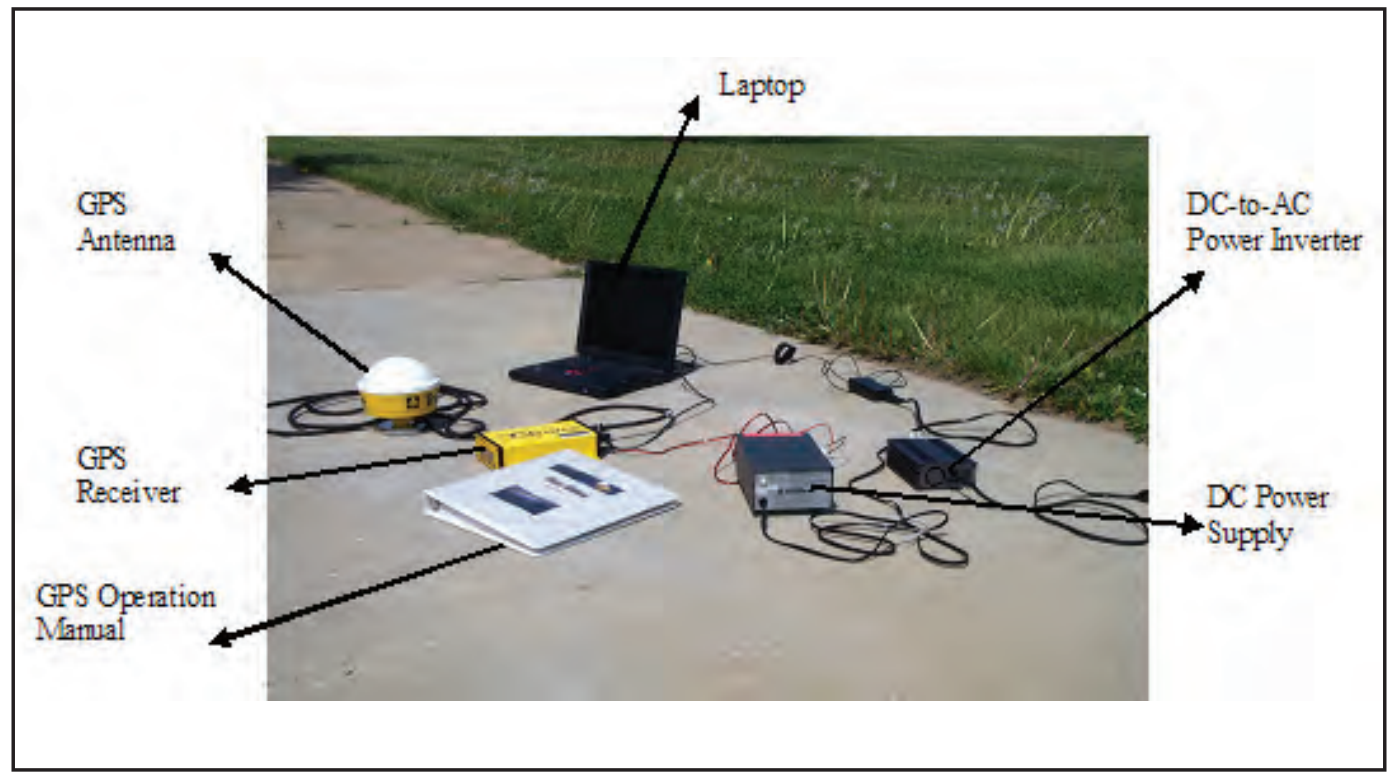


A computer program, GPS-Trek (Li et al. 2002), was developed specifically for this study so that GPS-recorded vehicle positioning data can be automatically processed and converted into a desired format with values of travel time, distance, and speed. GPS-Trek has an embedded Indiana GIS highway map and can display the trajectory of the test vehicle on the GIS map. The software allows users to initiate or to end a data collection session using designated keys on the computer keyboard. Users can monitor the data collection process while the roadway measured by GPS is displayed on the GIS map in real time. Users can press designated keys during data collection to mark special events or landmarks. Users also may enter comments at the beginning and the end of a data collection session. To identify the location of an intersection, a mark could be added to the data file manually by pressing a key on the computer keyboard during data collection. However, this operation would require constant operator intervention and would be error-prone. It would also result in safety concerns if data collection is performed by one operator who must drive the test vehicle and mark the intersection location at the same time. To avoid this unsafe operation, an intersection marking tool was designed in the GPS-Trek program. This tool allows the intersection location to be identified and marked after data collection. That is, the test vehicle travel process can be replayed on the GIS base map and the intersection location can then be marked on the base map during replay by clicking a selection cursor. The selection of the intersection location on the GIS base map will automatically add a mark at the corresponding distance point in the data file. With this feature of the software, only one operator is required for GPS data collection. For each test run, the operator activates the GPS-Trek program and then drives the test vehicle through the test route. When traveling on the test route, the operator does not need to do anything with the GPS system so that the driving operation will not be interrupted and cause safety concerns.

\section{IDENTIFICATION OF INTERSECTION DELAYS FROM GPS DATA}

Traffic delay at an intersection is most frequently quantified in the forms defined below (McShane et al. 1998):

- $\quad$ Stopped-time delay is the time a vehicle is stopped while waiting to pass through an intersection.

- Approach delay includes stopped-time delay and the time lost when a vehicle decelerates from its normal speed to a stop and accelerates from the stop to its normal speed.

- Travel-time delay is the difference between the actual time for a vehicle to pass the intersection and the time for the vehicle to pass the intersection at the driver's desired speed.

- Time-in-queue delay is the total time that elapses from a vehicle joining an intersection queue to its discharge from the queue across the stop-line.

Traffic engineers often measure stoppedtime delay in intersection studies because it is relatively easier to manually measure than other types of delays. With GPS devices, however, all of these delays can be directly obtained or indirectly derived from vehicle-positioning data.

Figure 4 (McShane et al. 1998) illustrates some typical intersection delays on a plot of distance vs. time of a vehicle's traveling positions. As can be seen, these intersection delays are measured based on the actual path and desired path of the vehicle traveling through the intersection. GPS vehicle-positioning data contains the test vehicle's position points at given time intervals. The GPS device in this study was set to record the test vehicle's positions at each second, which are the data points of distance vs. time. Therefore, as the test vehicle passes through an intersection, the actual path of the vehicle is being recorded. The desired path of the test vehicle cannot be directly recorded with GPS. However, the typical vehicle free-flow speed, or the desired 
Figure 4: Illustration of Intersection Delays

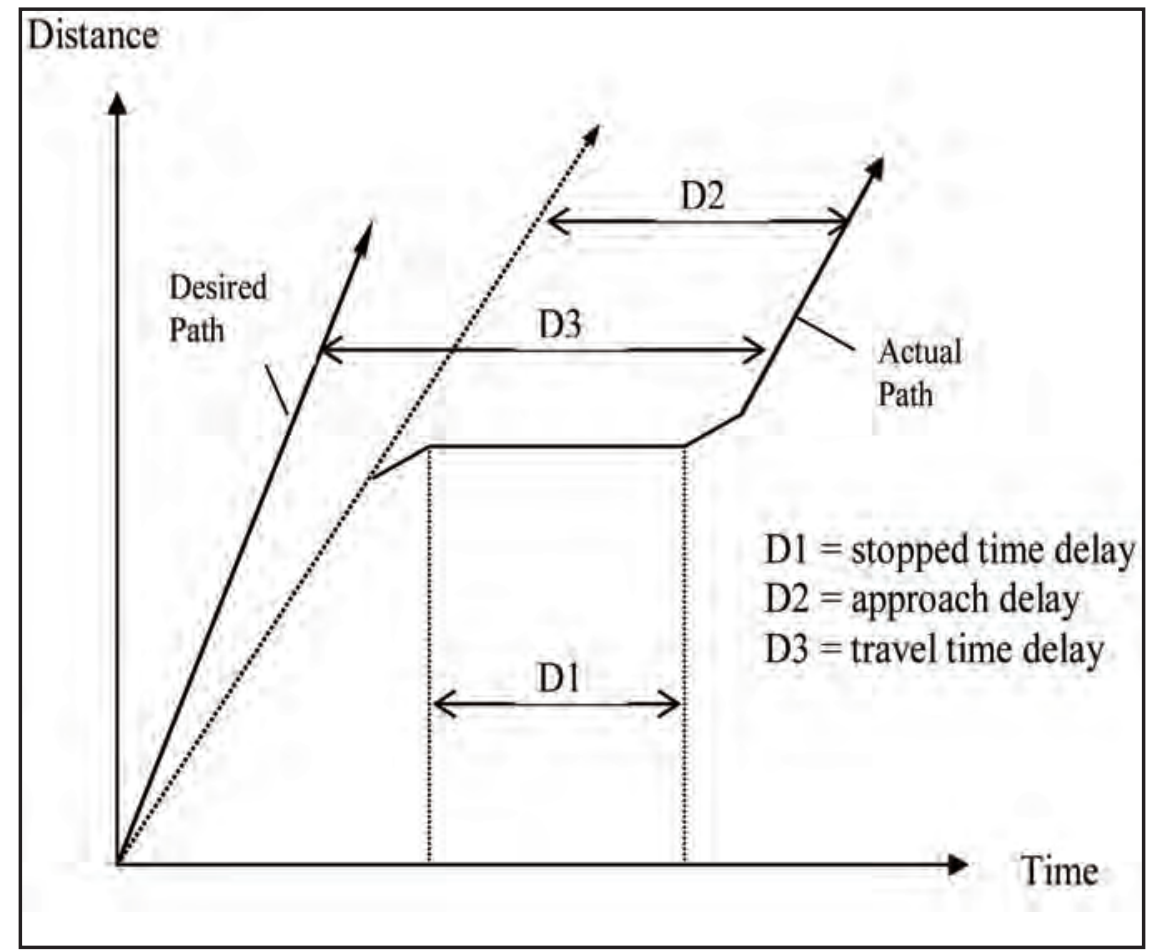

Source: McShane et al. (1998)

speed, can be measured by driving the test vehicle following the main traffic flow on a fairly distant upstream roadway section of the intersection. This desired speed should be measured where the upstream intersection is adequately distant from the intersection of interest and when the traffic volume is relatively low. An upstream intersection is the adjacent intersection before the subject intersection along the travel direction. If the upstream intersection is close to the intersection of interest, the test runs for the desired speed should include those in which the test vehicle arrived at the upstream intersection during green light and passed it without deceleration. Once this desired speed is determined, the desired path shown in Figure 4 can be plotted accordingly.

Note that all travel delays in Figure 4 are the delays of an individual vehicle. To estimate the total travel delays, traffic engineers will need to multiply the travel delay values by traffic volume. Because only the travel delays of individual vehicles are of interest, traffic volume was not measured in this study.
As an example, Figure 5 shows a distance vs. time plot with the GPS-recorded test vehicle's positioning data at the intersection of SR-26 and Creasy Lane. In this figure, the straight dotted line on the left hand side is the desired path and is drawn based on a measured desired speed of $77 \mathrm{~km} / \mathrm{h}$ (kilometers per hour). The desired speed was measured as the test vehicle approached the intersection at the driver's perceived traffic flow speed without interruptions of upstream traffic lights and under light traffic conditions. The curve on the right hand side is the actual path based on the GPS-recorded vehicle-positioning data. With the desired-path and the actual-path curves, the stopped-time delay, the approach delay, and the travel-time delay at the intersection can be measured in Figure 5 in the manner illustrated in Figure 4.

Note that one of the four listed intersection delays, i.e., time-in-queue delay, is not shown and thus cannot be obtained in Figure 4. However, all of the intersection delays, including time-in-queue delay, can be obtained 
Figure 5: GPS Recorded Test Vehicle's Distance vs. Time

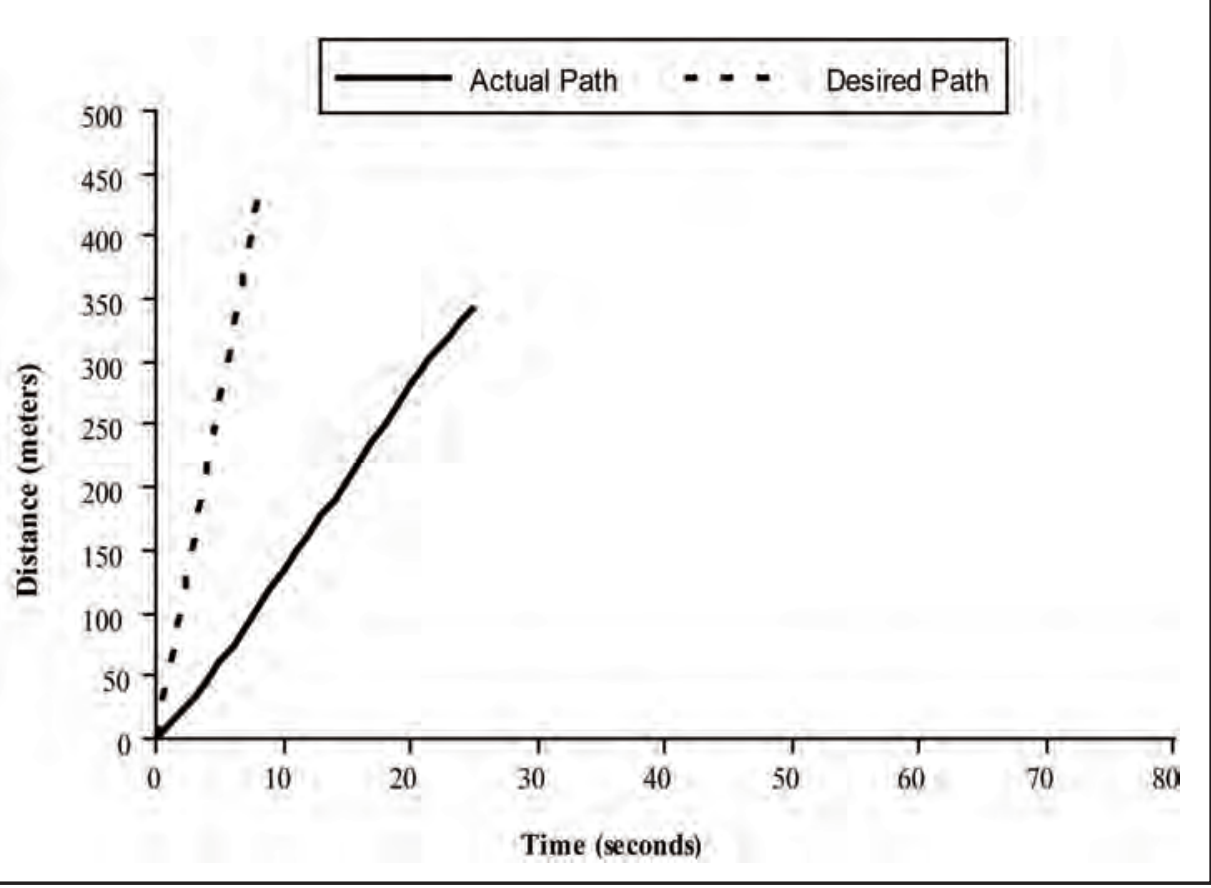

either directly or indirectly from a GPS-Trek generated data file without drawing such curves as presented in Figure 4. To demonstrate how to use a GPS-Trek output file to find intersection delays, part of the GPS-recorded data points, which were used to draw the actual path curve in Figure 5, are presented in Table 1. The test run was performed eastbound on SR-26, starting at 417.1 meters west of the intersection with Creasy Lane. The first four columns are the data values contained in the GPS-Trek data file, including time, distance, speed, and intersection mark. A value of zero in the fourth column indicates the starting point (the stopline) of the SR-26 and Creasy Lane intersection. The last two columns of the table are not part of the GPS output file, but are added to this table for explanation purpose.

In the fifth column of Table 1, the length of stopped-time delay is represented by the shaded area. This delay is simply the time period in which its speed was zero in front of the intersection. From the first and third columns, it can be seen that the vehicle speed was zero starting at the $34^{\text {th }}$ second and ending at the $58^{\text {th }}$ second. Thus, the stopped-time delay for this test run is $d_{s}=58-34=24$ seconds, which is the length of the area in the fifth column.

Time-in-queue delay is defined as the total time from a vehicle joining an intersection queue to its discharge across the stop-line. In the GPS output file as shown in Table 1, the beginning of the intersection (the stop-line) is marked with a " 0 " in the fourth column. The time-in-queue delay can then be directly obtained from the data file. In this example, the test vehicle stopped or joined the vehicle queue at the $34^{\text {th }}$ second (the starting time of speed $=$ 0 ) and moved across the stop-line at the $64^{\text {th }}$ second. Therefore, the time-in-queue delay is $\mathrm{d}_{\mathrm{q}}=64-34=30$ seconds, as shown by the area in the sixth column of Table 1.

As defined earlier, approach delay is the stopped-time delay plus the time lost during deceleration and acceleration as a vehicle passes through an intersection. Unlike stoppedtime delay or time-in-queue delay, approach delay and travel-time delay cannot be read directly from the GPS data file. However, they can be obtained from the GPS data file through simple calculations. To obtain the approach delay, the normal speed on the roadway section 
Table 1: GPS Recorded Data and Intersection Delays

\begin{tabular}{|c|c|c|c|c|c|}
\hline (1) & (2) & (3) & (4) & (5) & (6) \\
\hline $\begin{array}{l}\text { Time } \\
\text { (sec) }\end{array}$ & Distance (m) & Speed $(\mathbf{k m} / \mathbf{h})$ & $\begin{array}{c}\text { Intersection } \\
\text { Mark }\end{array}$ & $\begin{array}{l}\text { Stopped } \\
\text { Delay }\end{array}$ & $\begin{array}{l}\text { Time in } \\
\text { Queue }\end{array}$ \\
\hline 20 & 280.8 & 52.9 & & & \\
\hline 21 & 295.1 & 49.6 & & & \\
\hline 22 & 308.4 & 46.5 & & & \\
\hline 23 & 320.9 & 43.1 & & & \\
\hline 24 & 332.3 & 39.1 & & & \\
\hline 25 & 342.7 & 35.4 & & & \\
\hline 26 & 352.0 & 31.7 & & & \\
\hline 27 & 360.3 & 28.0 & & & \\
\hline 28 & 367.3 & 22.2 & & & \\
\hline 29 & 372.8 & 18.5 & & & \\
\hline 30 & 377.7 & 16.7 & & & \\
\hline 31 & 381.8 & 12.7 & & & \\
\hline 32 & 384.5 & 6.4 & & & \\
\hline 33 & 385.5 & 0.5 & & & \\
\hline 34 & 385.6 & 0.0 & & \multirow{13}{*}{$\begin{array}{c}\text { Stopped } \\
\text { Time Delay } \\
\text { (24 sec.) }\end{array}$} & \multirow{19}{*}{$\begin{array}{c}\text { Time In } \\
\text { Queue } \\
\text { Delay } \\
\text { (30 sec) }\end{array}$} \\
\hline 35 & 385.6 & 0.0 & & & \\
\hline 36 & 385.6 & 0.0 & & & \\
\hline$\cdot$ & $\cdot$ & $\cdot$ & • & & \\
\hline$\cdot$ & $\cdot$ & $\cdot$ & $\cdot$ & & \\
\hline & & 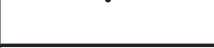 & 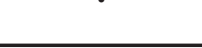 & & \\
\hline 51 & 385.7 & 0.0 & & & \\
\hline 52 & 385.7 & 0.0 & & & \\
\hline 53 & 385.7 & 0.0 & & & \\
\hline 54 & 385.7 & 0.0 & & & \\
\hline 55 & 385.7 & 0.0 & & & \\
\hline 56 & 385.7 & 0.0 & & & \\
\hline 57 & 385.7 & 0.0 & & & \\
\hline 58 & 386.6 & 5.6 & & & \\
\hline 59 & 389.2 & 12.9 & & & \\
\hline 60 & 393.7 & 19.5 & & & \\
\hline 61 & 400.0 & 25.7 & & & \\
\hline 62 & 407.9 & 30.7 & & & \\
\hline 63 & 417.1 & 35.6 & $\mathbf{0}$ & & \\
\hline 64 & 427.6 & 40.2 & & & \\
\hline 65 & 439.3 & 43.9 & & & \\
\hline 66 & 452.0 & 47.5 & & & \\
\hline 67 & 465.6 & 50.5 & & & \\
\hline 68 & 479.9 & 52.5 & & & \\
\hline
\end{tabular}


must be identified from the GPS data. The normal speed should be the stable speed of the test vehicle when it is not interrupted by intersection signals. As shown in Table 2, the normal speed is the average value of the speeds during the first 20 seconds before the vehicle started to decelerate in front of the intersection, which is $53 \mathrm{~km} / \mathrm{h}$. As shown in Table 1 and Figure 5, the test vehicle started to decelerate at the $20^{\text {th }}$ second and the distance point of 280.8 meters and it resumed its normal speed at the $68^{\text {th }}$ second and the distance point of 479.9 meters. The actual time spent is $\mathrm{T}=68-20$ $=48$ seconds and the distance traveled is $\mathrm{D}=$ $479.9-280.8=199.1$ meters. The approach delay is then the difference between the actual travel time $\mathrm{T}$ over distance $\mathrm{D}$ and the time it would be required to travel the same distance at the normal speed. That is, the approach delay can be computed using the following equation:

Table 2: Calculation of Normal Speed from GPS Data

\begin{tabular}{|c|c|c|}
\hline Time (sec) & Speed (km/h) & Comments \\
\hline 0 & 53.1 & \multirow{21}{*}{$\begin{array}{l}\text { The normal speed is the stable speed of the } \\
\text { test vehicle when it is not interrupted by } \\
\text { intersection signals. } \\
\text { Normal speed is the average value of speeds } \\
\text { during the first } 20 \text { seconds, which is } 53 \mathrm{~km} / \mathrm{h}\end{array}$} \\
\hline 1 & 53.9 & \\
\hline 2 & 52.9 & \\
\hline 3 & 54.3 & \\
\hline 4 & 54.0 & \\
\hline 5 & 50.4 & \\
\hline 6 & 52.6 & \\
\hline 7 & 54.5 & \\
\hline 8 & 54.9 & \\
\hline 9 & 53.4 & \\
\hline 10 & 52.1 & \\
\hline 11 & 50.7 & \\
\hline 12 & 49.4 & \\
\hline 13 & 49.1 & \\
\hline 14 & 51.0 & \\
\hline 15 & 52.8 & \\
\hline 16 & 54.7 & \\
\hline 17 & 56.0 & \\
\hline 18 & 55.5 & \\
\hline 19 & 54.2 & \\
\hline 20 & 52.9 & \\
\hline 21 & 49.6 & \multirow{14}{*}{ Deceleration period. } \\
\hline 22 & 46.5 & \\
\hline 23 & 43.1 & \\
\hline 24 & 39.1 & \\
\hline 25 & 35.4 & \\
\hline 26 & 31.7 & \\
\hline 27 & 28.0 & \\
\hline 28 & 22.2 & \\
\hline 29 & 18.5 & \\
\hline 30 & 16.7 & \\
\hline 31 & 12.7 & \\
\hline 32 & 6.4 & \\
\hline 33 & 0.5 & \\
\hline 34 & 0.0 & \\
\hline
\end{tabular}


(2) $d_{a}=T-3.6 \frac{D}{v_{n}}$

where

$\mathrm{d}_{\mathrm{a}}=$ approach delay, seconds.

$\mathrm{T}=$ time period from starting deceleration to completing acceleration, seconds.

$\mathrm{D}=$ distance traveled during time $\mathrm{T}$, meters.

$\mathrm{v}_{\mathrm{n}}=$ vehicle's normal speed, $\mathrm{km} / \mathrm{h}$.

3.6 = factor to convert time unit to seconds.

With the normal speed of $53 \mathrm{~km} / \mathrm{h}$ and data

in Table 1, the approach delay can be calculated as $\mathrm{d}_{\mathrm{a}}=48-3.6(199.1 / 53)=34.5$ seconds.

Similar to Equation 2, the travel-time delay can be obtained using the following equation:

(3) $d_{t}=T-3.6 \frac{D}{v_{d}}$

where

$\mathrm{d}_{\mathrm{t}}=$ travel-time delay, seconds.

$\mathrm{v}_{\mathrm{d}}=$ desired speed, seconds.

$\mathrm{T}$ and $\mathrm{D}$ are as defined in Equation 2.

The only difference between the two equations is that desired speed is used in Equation 3 and normal speed is used in Equation 2. As explained above, desired speed should be measured when approaching traffic flow is relatively low and is not interrupted by traffic signals. On this section of roadway, the desired speed was about $77 \mathrm{~km} / \mathrm{h}$ under good travel conditions. With this value of the desired speed, the travel-time delay can be computed with Equation 3 as $d_{t}=48-3.6(199.1 / 77)=38.7$ seconds.

\section{PERFORMANCE OF COORDINATED INTERSECTIONS}

The study sections on US-31 and SR-26 are used in the following to illustrate the application of the collected GPS data on the performance of coordinated intersections. The main demonstration of the performance analysis focuses on the seven intersections on US-31, while the SR-26 section is used to present an example of segment performance of coordinated intersections. Table 3 presents the mean values of the four types of intersection delays measured by GPS at the seven intersections. Because the seven intersection signals on US-31 are coordinated, the delays at these intersections show not only the performance of individual intersections, but also the performance of the coordinated intersection system. The relatively long delays at Lincoln and Markland intersections, as shown in Table 3, could be an indication that the signal coordination was not as good as desired and improvement in signal timing design might be necessary.

In addition to the mean values of intersection delays, more detailed information can be provided with GPS-collected vehicle positioning data. For instance, the measured stopped-time delays for each test run and the standard deviations are include in Table 4 along with the mean stopped-time delays at the intersections. As can be seen, vehicles consistently endured relatively long delays in all six test runs at the Markland intersection.

Table 3: GPS Measured Mean Intersection Delays

\begin{tabular}{|c|c|c|c|c|c|}
\hline \multirow{3}{*}{ Road } & Intersection & $\begin{array}{c}\text { Stopped } \\
\text { Time Delay } \\
\text { (seconds) }\end{array}$ & $\begin{array}{c}\text { Time in } \\
\text { Queue Delay } \\
\text { (seconds) }\end{array}$ & $\begin{array}{c}\text { Approach } \\
\text { Delay } \\
\text { (seconds) }\end{array}$ & $\begin{array}{c}\text { Travel } \\
\text { Time Delay } \\
\text { (seconds) }\end{array}$ \\
\hline \multirow{5}{*}{ US-31 } & Lincoln & 31.3 & 35.0 & 43.7 & 48.3 \\
\cline { 2 - 6 } & Southway & $\mathbf{0 . 0}$ & $\mathbf{0 . 0}$ & $\mathbf{0 . 0}$ & 1.5 \\
\cline { 2 - 6 } & Hoffer & $\mathbf{0 . 0}$ & $\mathbf{0 . 0}$ & $\mathbf{0 . 0}$ & $\mathbf{0 . 7}$ \\
\cline { 2 - 6 } & Savoy & $\mathbf{0 . 0}$ & $\mathbf{0 . 0}$ & $\mathbf{0 . 0}$ & 1.1 \\
\cline { 2 - 6 } & Markland & 59.3 & $\mathbf{6 9 . 2}$ & $\mathbf{8 1 . 5}$ & $\mathbf{8 9 . 2}$ \\
\cline { 2 - 6 } & Carter & 2.8 & $\mathbf{8 . 4}$ & 10.2 & 14.3 \\
\cline { 2 - 6 } & Sycamore & $\mathbf{0 . 0}$ & $\mathbf{0 . 0}$ & $\mathbf{0 . 0}$ & 1.2 \\
\hline
\end{tabular}


Table 4: Statistics of GPS Measured Stopped Time Delays (seconds)

\begin{tabular}{|c|c|c|c|c|c|c|c|c|c|}
\hline Road & Intersection & $\begin{array}{c}\text { Run } \\
\# 1\end{array}$ & $\begin{array}{c}\text { Run } \\
\# 2\end{array}$ & $\begin{array}{c}\text { Run } \\
\# 3\end{array}$ & $\begin{array}{c}\text { Run } \\
\# 4\end{array}$ & $\begin{array}{c}\text { Run } \\
\# 5\end{array}$ & $\underset{\# 6}{\text { Run }}$ & Mean & $\begin{array}{l}\text { Standard } \\
\text { Deviation }\end{array}$ \\
\hline \multirow{7}{*}{ US-31 } & Lincoln & 32 & 49 & 46 & 43 & 18 & 0 & 31.3 & 19.1 \\
\hline & Southway & 0 & 0 & 0 & 0 & 0 & 0 & 0.0 & 0.0 \\
\hline & Hoffer & 0 & 0 & 0 & 0 & 0 & 0 & 0.0 & 0.0 \\
\hline & Savoy & 0 & 0 & 0 & 0 & 0 & 0 & 0.0 & 0.0 \\
\hline & Markland & 60 & 50 & 65 & 62 & 61 & 58 & 59.3 & 5.1 \\
\hline & Carter & 6 & 0 & 0 & 0 & 8 & 0 & 2.3 & 3.7 \\
\hline & Sycamore & 0 & 0 & 0 & 0 & 0 & 0 & 0 & 0 \\
\hline
\end{tabular}

Vehicles also experienced some delays at the Lincoln intersection in all but one test run. At the Carter intersection there were only minimal traffic delays, and at the other four intersections there were no traffic delays during the test period. The values of the standard deviations in Table 4 indicate that the Markland intersection experienced lower deviations of traffic delays than the Lincoln intersection even though the Markland intersection had a higher mean traffic delay.
To further study the effectiveness of the coordinately controlled intersections on US-31, Figures 6 and 7 can be drawn to examine the speed patterns of the test vehicle recorded by GPS. Because the test vehicle traveled with traffic stream, the two figures also represent the speed patterns of traffic flow. Figure 6 depicts a speed profile of the test vehicle from Lincoln to Sycamore. It illustrates that the test vehicle either stopped or slowed down in front of some of the intersections. Figure 7 presents the

Figure 6: GPS Recorded Speed Profile on US-31 Segment

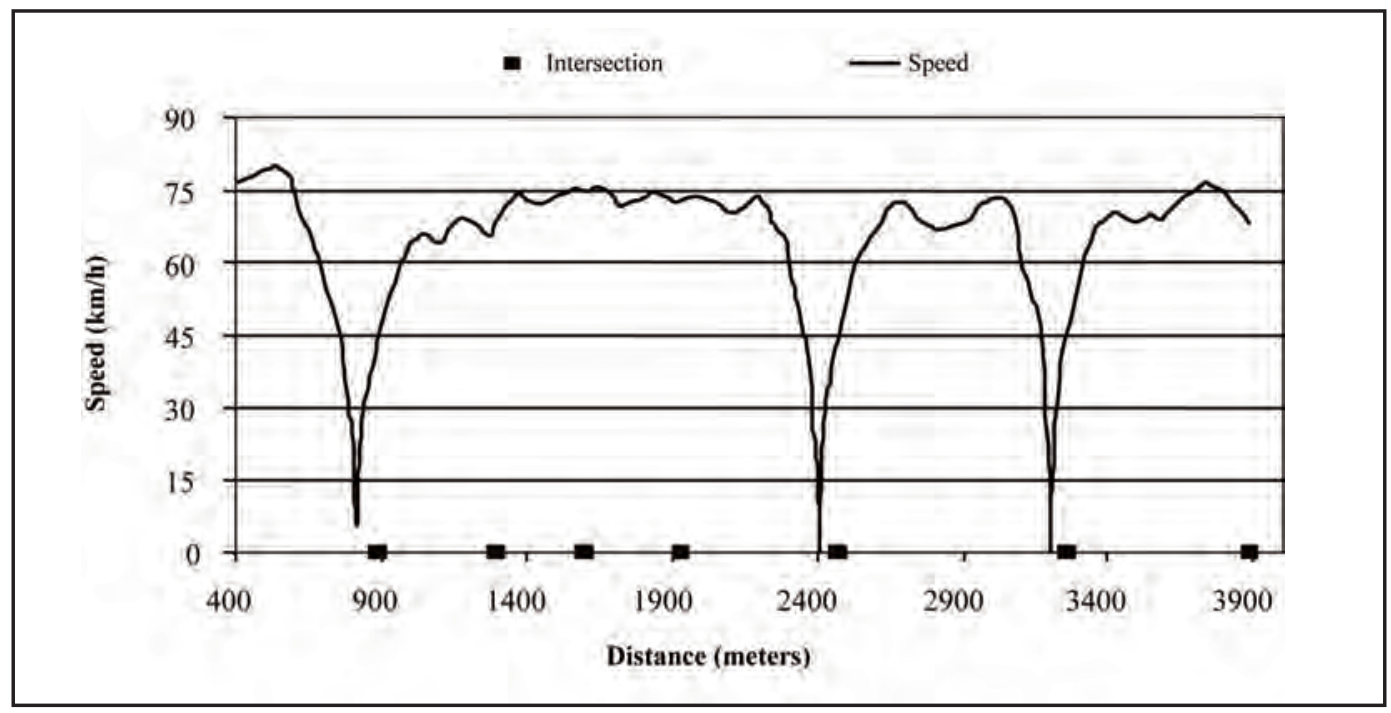




\section{Figure 7: Average Speed Between Intersections}

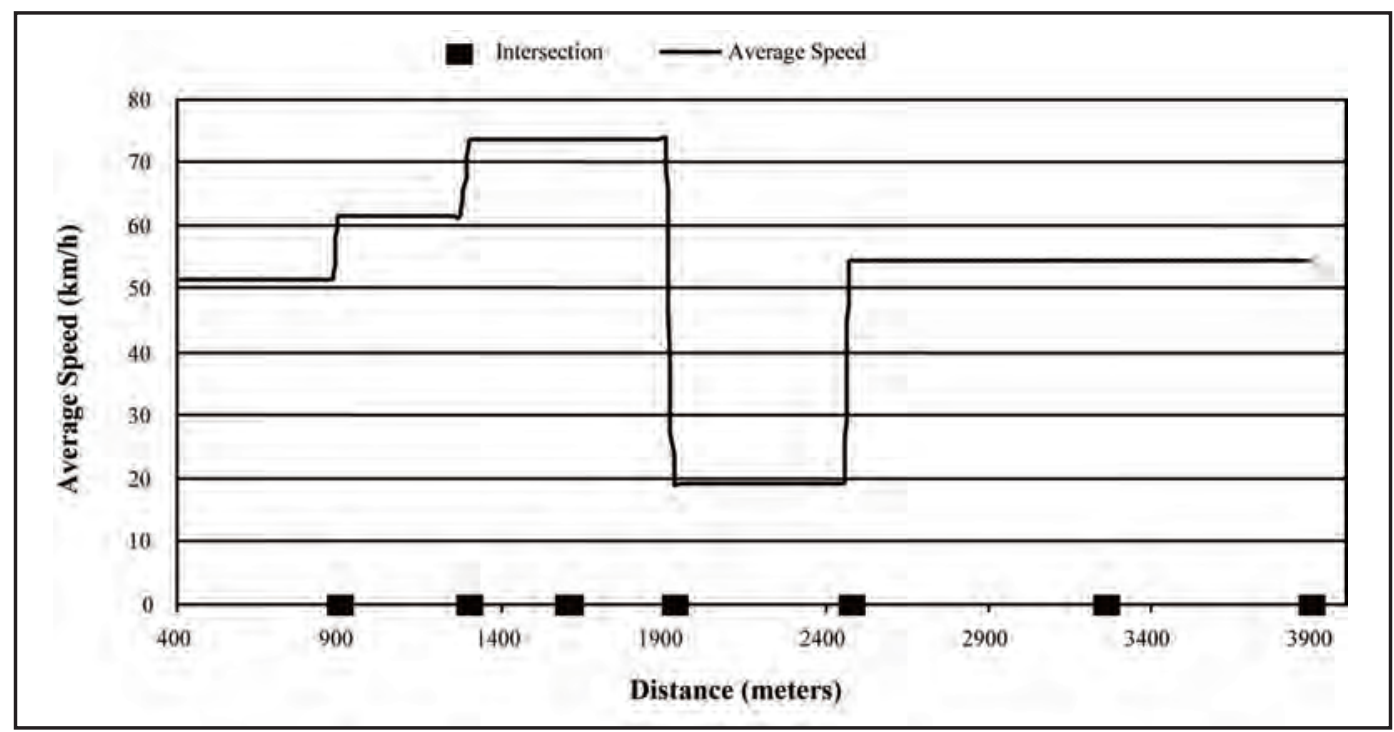

average speeds on the roadway sections between adjacent intersections. It shows in Figure 7 that the lowest average speed occurred on the roadway section between the fourth (Savoy) and fifth (Markland) intersections. This is expected because the longest intersection delays were observed at the fifth intersection (Markland), as shown in Tables 3 and 4.

As discussed above, GPS-collected data provides detailed information on intersection delays and vehicle speeds. With GPS data, the performance of individual intersections as well as coordinated intersections can be analyzed in terms of intersection delays and speed patterns. Moreover, the total delay at the coordinated intersections on US-31 can also be derived from the GPS data with the following equation:

(4) $d_{\text {total }}=T-3.6 \frac{D}{v_{d}}$

where

$\mathrm{d}_{\text {total }}=$ total delay at coordinated intersections, seconds.

$\mathrm{T}=$ actual time traversing a given distance that covers all coordinated intersections, seconds.

$\mathrm{D}=$ distance that covers all coordinated intersections, meters.

$\mathrm{v}_{\mathrm{d}}=$ vehicle's desired speed, $\mathrm{km} / \mathrm{h}$.

3.6 = factor to convert time unit to seconds.

Equation 4 is in the same form as Equation

3. The only difference is that the distance (D) in
Equation 4 covers all coordinated intersections rather than an individual intersection. In Equation 4, the actual travel time is measured with GPS and the desired travel time can be calculated with a desired speed and the GPSmeasured distance corresponding to the actual travel time.

The calculated results based on Equation 4 for the US-31 section with the coordinated intersections are listed in Table 5. The measured stopped-time delay is the sum of stopped-time delays at the seven intersections. The "other delay" shown in the last row of Table 5 is the difference between the total delay and the measured stopped-time delay. The total delay data in Table 5 provides an overall measure of the performance of the coordinated intersections, while the delay and speed data in Tables 3 and 4 as well as in Figures 6 and 7 contains more detailed information on the performance of individual intersections.

As previously discussed, several types of traffic delays can be identified using curves as illustrated in Figure 4, which is a curve of travel distance versus travel time. To study the performance of coordinated intersections, however, a curve of travel time versus travel distance can be utilized to illustrate the locations and the magnitudes of traffic delays. Figure 8 is a chart of travel time versus distance of the testing vehicle based on the GPS-recorded 
Table 5: Traffic Delays on the US-31 Coordinated Intersection System

\begin{tabular}{|c|c|c|c|c|c|c|c|}
\hline & Run 1 & Run 2 & Run 3 & Run 4 & Run 5 & Run 6 & Mean \\
\hline Distance (m) & 3888.2 & 3897.7 & 3895.6 & 3896.8 & 3903.2 & 3904.5 & 3897.7 \\
\hline $\begin{array}{c}\text { Actual Travel } \\
\text { Time (sec) }\end{array}$ & 310.0 & 319.0 & 310.5 & 303.5 & 320.5 & 297.5 & 310.2 \\
\hline $\begin{array}{c}\text { Measured } \\
\text { Average Speed } \\
\text { (km/h) }\end{array}$ & 45.2 & 44.0 & 45.2 & 46.2 & 43.8 & 47.2 & 45.3 \\
\hline $\begin{array}{c}\text { Desired Speed } \\
\text { (km/h) }\end{array}$ & 90.0 & 90.0 & 90.0 & 90.0 & 90.0 & 90.0 & 90.0 \\
\hline $\begin{array}{c}\text { Desired Travel } \\
\text { Time (sec) }\end{array}$ & 155.5 & 155.9 & 155.8 & 155.9 & 156.1 & 156.2 & 155.9 \\
\hline $\begin{array}{c}\text { Total Delay } \\
\text { (sec) }\end{array}$ & 154.5 & 163.1 & 154.7 & 147.6 & 164.4 & 141.3 & 154.3 \\
\hline $\begin{array}{c}\text { Measured } \\
\text { Stopped Time } \\
\text { Delay (sec) }\end{array}$ & 98.0 & 99.0 & 111.0 & 105.0 & 87.0 & 58.0 & 93.0 \\
\hline $\begin{array}{c}\text { Other Delay } \\
\text { (sec) }\end{array}$ & 56.5 & 64.1 & 43.7 & 42.6 & 77.4 & 83.3 & 61.3 \\
\hline
\end{tabular}

traffic data on SR-26. A vertical portion of the curve indicates a location where the vehicle stopped and the durations of the vehicle stop. The duration of each vehicle stop is a stopped delay. Therefore, the values of the stopped delays can be read directly from the curve or from the GPS recorded data. In this case, the vehicle stopped in front of the sixth (Farington Avenue) and the seventh (Wellspring Drive) intersections. The values of the stopped delays are 41 seconds for the sixth intersection and 15 seconds for the seventh intersection. These are the recorded time durations corresponding to the speed values of zero or the length of the vertical segments of the curve.

With the GPS data, the travel delays of any section between two intersections of coordinated intersections can be obtained through Equation 3. Table 6 presents the delay values on the SR-26 section, including delays on individual sections between any two consecutive intersections as well as on the whole section of the eight intersections. The average delays in terms of travel delay per unit length of roadway in Table 6 can be used as a measure of segment performance of the coordinated intersection system.

\section{CONCLUSIONS}

With GPS-collected traffic data of two coordinated intersection systems, this paper presents the techniques for identifying and measuring various types of intersection delays, graphical representations of coordinated intersection delays, and performance analyses of coordinated intersections. The GPS-collected travel data along the test road segments contains detailed information on vehicle positions and travel speeds, so various travel delays at the coordinated intersections can be obtained. The travel delays, the vehicle speed profiles, and the average speed values between intersections provide essential information for traffic engineers to identify problem intersections and time periods in the coordinated intersection 


\section{Figure 8: Vehicle Travel Time Versus Distance on SR-26}

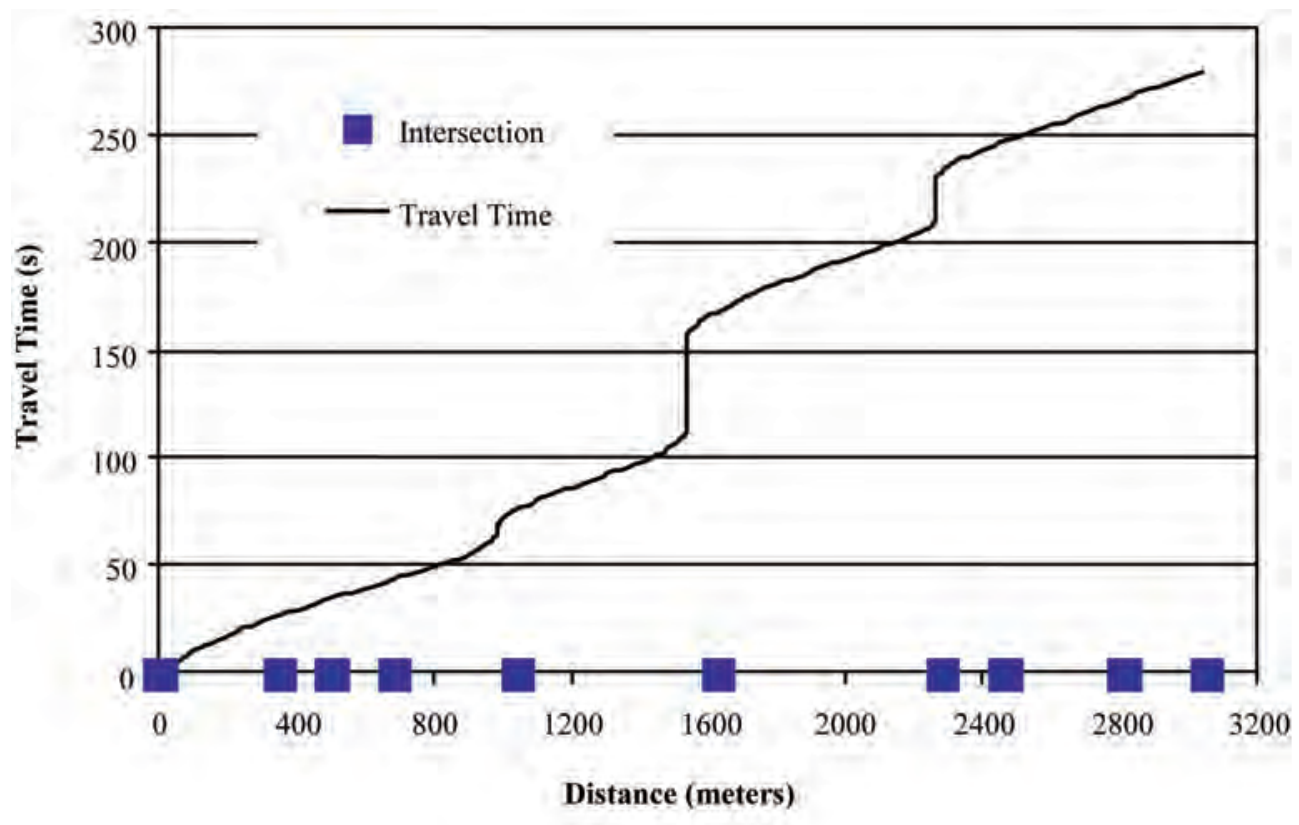

Table 6: Travel Delays at Coordinated Intersections on SR-26

\begin{tabular}{|c|c|c|c|}
\hline Section & $\begin{array}{c}\text { Delay Between } \\
\text { Intersections } \\
\text { (seconds) }\end{array}$ & $\begin{array}{c}\text { Distance of } \\
\text { Section }(\mathbf{k m})\end{array}$ & $\begin{array}{l}\text { Average Delay } \\
\text { (seconds/km) }\end{array}$ \\
\hline From intersection 1 to 2 & 9.94 & 0.354 & 28.05 \\
\hline From intersection 2 to 3 & 0.72 & 0.145 & 4.98 \\
\hline From intersection 3 to 4 & 0.31 & 0.187 & 1.66 \\
\hline From intersection 4 to 5 & 15.80 & 0.357 & 44.22 \\
\hline From intersection 5 to 6 & 64.38 & 0.580 & 110.99 \\
\hline From intersection 6 to 7 & 58.45 & 0.657 & 88.90 \\
\hline From intersection 7 to 8 & 5.16 & 0.179 & 28.90 \\
\hline From intersection 8 to 9 & 3.70 & 0.348 & 10.62 \\
\hline From intersection 9 to 10 & 1.83 & 0.239 & 7.67 \\
\hline
\end{tabular}


system. Consequently, the traffic engineers would be able to address the problems effectively with appropriate remedy actions.

To ensure a desired accuracy, an appropriate sample size must be determined as described in this paper. It should be noted that a GISbased map was used as an integral part of the GPS data collection and analysis. It is found in this study as well as in many other studies that the GPS and GIS technologies have generally been applied in combination. Therefore, except when an individual intersection or a fixed point of a roadway is to be evaluated, it is strongly recommended that a GIS-based map be available for GPS applications. The use of a GIS-based map can greatly improve the effectiveness of GPS applications in roadway sections and highway networks. It should also be noted that a computer interface program that converts GPS data into values of travel time, travel distance, and vehicle speed is not always available with GPS devices. In this study, it was necessary to develop the computer program, GPS-Trek, to facilitate GPS operation and data collection.

As the prices of GPS devices decrease and the GPS technologies continuously improve, the applications of GPS in traffic studies will certainly grow. In addition to intersection performance, GPS devices have been utilized in many other highway and traffic related areas, such as traffic delays at work zones, traffic surveillance, and traffic model verifications. It is believed that more applications of GPS devices in traffic engineering will be explored and adopted in the future.

\section{References}

Jiang, Y. and S. Li. "Measuring and Analyzing Vehicle Position and Speed Data at Work Zones Using Global Positioning System.” ITE Journal 72(3), (2002): 48-53.

Jiang, Y., S. Li, and K. Q. Zhu. "Applications of Global Positioning System in Traffic Data Collections." Proceedings of the Third International Conference on Traffic and Transportation Studies, (2002): 1322-1329.

Li, S., K. Zhu, B. H. W. van Gelder, J. Nagle, and C. Tuttle. Improving Efficiency of INDOT Traffic Data Collection Using GPS Devices. Final Report, FHWA/IN/JTRP-2002/19, 2002.

McNally, M.G., J.E. Marca, C.R. Rindt, and A.M. Koos. TRACER: In-vehicle, GPS-based, Wireless Technology for Traffic Surveillance and Management. California PATH Research Report, UCB-ITS-PRR-2003-23, 2003.

McShane, W. R., R. P. Roess, and E. S. Prassas. Traffic Engineering, Second Edition, Prentice Hall, Upper Saddle River, New Jersey, 1998.

Quiroga, C. A. and D. Bullock. Development of CMS Monitoring Procedures. Louisiana Transportation Research Center, Louisiana, 1998a.

Quiroga, C.A. and D. Bullock. "Travel Time Studies With Global Positioning and Geographic Information Systems: An Integrated Methodology.” Transportation Research Part C 6 , (1998b): 101-127.

Ranjitkar, P., T. Nakatsuji, and M. Asano. "Performance Evaluation of Microscopic Traffic Flow Models with Test Track Data.” Transportation Research Record 1876, (2004): 90-100.

Turner, S.M. “Advanced Techniques for Travel Time Data Collection,” Transportation Research Record 1551, (1996): 51-58.

Van Aerde, M., B. Hellinga, L. Yu, and H. Rakha. "Vehicle Probes as Real-Time ATMS Sources of Dynamic O-D and Travel Time Data.” Large Urban Systems - Proceedings of the ATMS Conference, (1993): 207-230.

Wolshon, B. and Y. Hatipkarasulu. "Results of Car Following Analyses Using Global Positioning System.” Journal of Transportation Engineering 126(4), (2000): 324-331. 
Yi Jiang, Ph.D., P.E., is an assistant professor in the Department of Building Construction Management at Purdue University. Prior to joining the Purdue University faculty, he worked as a highway engineer and section manager at the Indiana Department of Transportation and as an assistant professor in the Tennessee Technological University. He received his B.S. degree in civil engineering from Tongji University in China, and his M.S. and Ph.D. degrees in civil engineering from Purdue University.

Shuo Li, Ph.D., P.E., is a transportation research engineer with the Research Division, Indiana Department of Transportation. He received his B.S. degree from Tongji University in China, M.S. degree in civil engineering from Changan University in China, and Ph.D. degree in civil engineering from National University of Singapore.

Zhonghua Zhao is the chief engineer of Tianjin Municipal Engineering Administration in China. He is a Ph.D. candidate at Tianjin University in China. He received his B.S. degree in civil engineering from Tongji University in China. He has worked in various areas in infrastructure engineering and construction, including highways, bridges, and subways. 